\title{
Analysis of Tow Cables
}

\author{
Nimmy Thomas*, Manoj T. Issac \\ Department of Ship Technology, Cochin University of Science and Technology, India
}

Copyright $(2017$ by authors, all rights reserved. Authors agree that this article remains permanently open access under the terms of the Creative Commons Attribution License 4.0 International License

\begin{abstract}
Hydrodynamic analysis of tow cable has an important role in the design of towed system. Cable catenary, cable depth attained for a given cable length, cable tension and angle of cable with the body are the parameters that affects the towed system related to tow cable. This paper deals with analysis of a set of commercially available cables of different properties using Orcaflex software. The cables were analysed for different payouts at different speeds. A comparative study was performed on the results obtained relating the cable properties (diameter and buoyancy). This provides a rough idea on the catenary profiles that reflects the depth and trail achieved by the cable given payout and speed.
\end{abstract}

Keywords Tow Cables, Orcaflex, Catenary Profile, Towfish, Trail, Lumped Mass, Drag Coefficient

\section{Introduction}

The components of a towed system include towing ship, tow cable and the tow body. Underwater towed systems can be as simple as a single cable with its towed vehicle, or they may be composed of multiple towed cables and multiple towed bodies. They are employed for geophysical explorations, coastal surveillance, patrolling of offshore installations, detection of underwater targets, mine sweeping, surveys, inspections and researches.

In simulating the hydrodynamic performance of an underwater towed system, the coupling effect between the towing ship and the towed system is generally neglected, and the hydrodynamic model is usually composed of tow cable and towed body [1]. The towed body is towed behind the surface vessel by means of a tow cable. The depth at which the towed body is operated can be adjusted by varying the length of cable payout or by changing the ship speed or both. The horizontal distance between tow body and the towing ship is the trail. The angle that the cable makes with the horizontal is its 'critical angle', and is a function of towing speed, weight in water, and drag coefficient.

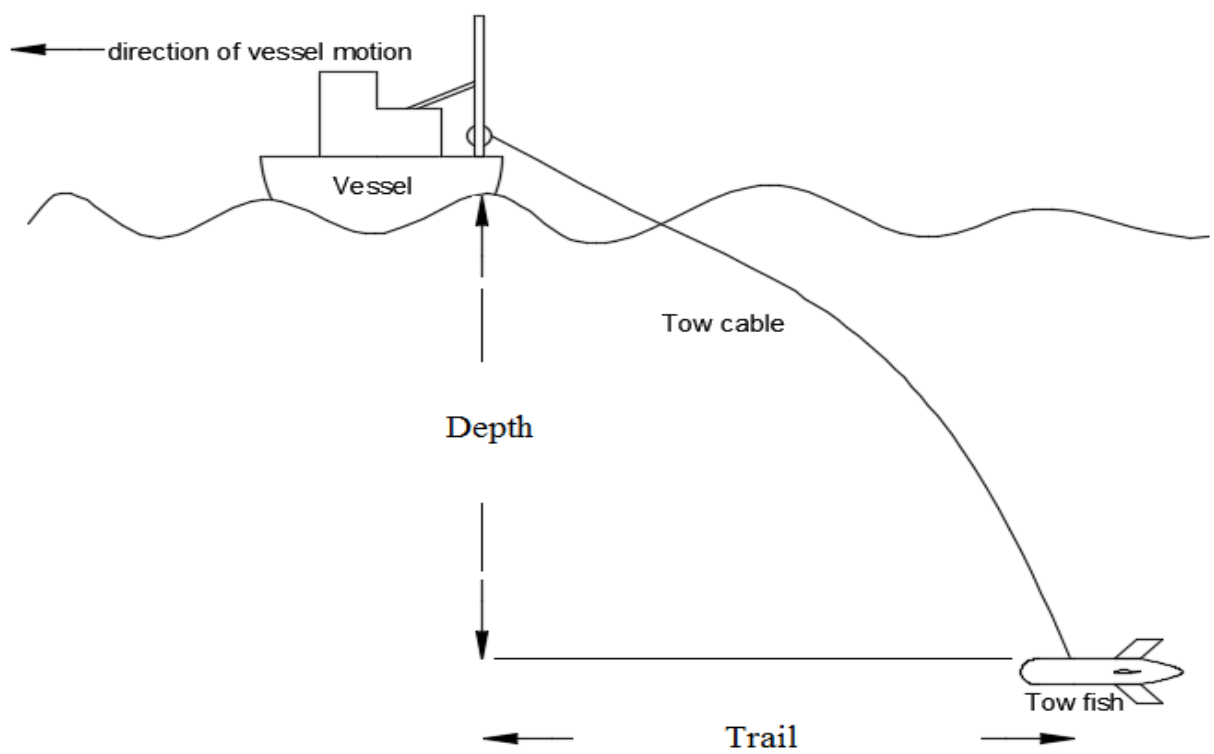

Figure 1. Schematic diagram of a towing arrangement 


\section{Modeling and Analysis\{ XE "template" \}}

The entire system was modelled as a combination of lines and a 3-D buoy to represent the towing system. The towed body is idealized as a 3-D buoy in Orcaflex [8]. The properties of 3D buoy are assumed as the parameters of a bare hull from reference [4]. The steady state configuration of the towed system is determined using implicit time domain analysis.

The cable is represented as a line in Orcaflex. This models cable as finite elements that are connected by frictionless spherical joints, i.e., the method employs lumped mass approach [1][2][3]. Orcaflex calculates tension forces, bend moments, shear forces, torsion moments and total load. The end fitting of the line is defined by 3 angles: azimuth, declination and gamma. 3-D buoys have the freedom of translational motion in $\mathrm{X}, \mathrm{Y}$ and $\mathrm{Z}$ directions. They do not rotate and therefore do not have rotational properties and moments. The equilibrium position of buoy is calculated by static analysis. The mass, volume, bulk modulus, height, contact area, drag coefficients, drag area and added mass coefficients are the parameters that defines the 3-D buoy. The seastate is assumed to be calm (glassy), and sea bed is assumed at $500 \mathrm{~m}$ depth. Angle of attack of towed body is assumed to be zero for any speed.
The cables chosen are commercially available tow cables and the strength details of cables are from the manufacture brochures. A variety of light tow cables, heavy tow cables and positively buoyant tow cables are selected for analysis.

The cables with codes 1SSA and 1HRS are of company NOVACAVI [7] and cables with codes starting FCE are of company FALMAT [6]. The description details of tow cables are available in the respective references.

\section{Results}

Analysis of selected 13 cables were performed in Orcaflex software for payout lengths of $100 \mathrm{~m}, 200 \mathrm{~m}, 300 \mathrm{~m}$ and $400 \mathrm{~m}$ at low speeds $2 \mathrm{~m} / \mathrm{s}$ to $10 \mathrm{~m} / \mathrm{s}$ at intervals of $2 \mathrm{~m} / \mathrm{s}$. The translational motion of towing vessel was restricted in global X-direction. Each simulation was performed at a constant speed for a time period of 600 seconds at time step 0.1 second. Each cable was discretized at $1 \mathrm{~m}$ intervals. The results at the 600th second instant were chosen for discussion. Total force, position and orientation of buoy and each node are obtained from simulation. The forces acting at the midpoint of each segment are also available from the analysis results. Detailed results are available in reference [5].

Table 1. Physical and hydrodynamic parameters of towing cable

\begin{tabular}{|c|c|c|c|c|c|}
\hline Sl.No & Cable Code & $\begin{array}{c}\text { Breaking } \\
\text { Strength }(\mathrm{N})\end{array}$ & $\begin{array}{c}\text { Overall } \\
\text { Dia(mm) }\end{array}$ & $\begin{array}{l}\text { Weight } \\
(\mathrm{kg} / \mathrm{m})\end{array}$ & $\begin{array}{c}\text { Weight/Buoyancy (W/B) } \\
\text { Ratio }\end{array}$ \\
\hline \multicolumn{6}{|c|}{ LIGHT TOW CABLES } \\
\hline 1 & FCE5020T05 & 1124 & 9.4 & 0.09673 & 1.36 \\
\hline 2 & FCE5020T20 & 4996 & 13 & 0.16965 & 1.23 \\
\hline 3 & FCE7514T02 & 562 & 22.9 & 0.54318 & 1.29 \\
\hline 4 & FCE7514T20 & 4996 & 25.4 & 0.63693 & 1.23 \\
\hline \multicolumn{6}{|c|}{ HEAVY TOW CABLES } \\
\hline 5 & $1 \mathrm{SSA} 4$ & 712000 & 11.45 & 0.441 & 4.18 \\
\hline 6 & 1SSA6 & 166713 & 17.3 & 0.968 & 4.02 \\
\hline 7 & 1SSA13 & 313812 & 24 & 1.798 & 3.88 \\
\hline 8 & 1SSA16 & 529559 & 9.95 & 0.352 & 4.42 \\
\hline \multicolumn{6}{|c|}{ LIGHT TOW CABLES } \\
\hline 9 & 1HRS255 & 3924 & 7.8 & 0.072 & 1.47 \\
\hline 10 & 1HRS259 & 3433 & 11 & 0.15 & 1.54 \\
\hline 11 & 1HRS285 & 3139 & 5 & 0.028 & 1.39 \\
\hline \multicolumn{6}{|c|}{ POSITIVELY BUOYANT CABLES } \\
\hline 12 & DYNEEMA [9] & 498200 & 25.4 & 0.00102 & 0.002 \\
\hline 13 & KEVLAR [10] & 346961 & 25.4 & 0.0015 & 0.003 \\
\hline
\end{tabular}

Table 2. Physical and hydrodynamic parameters of towed body [1]

\begin{tabular}{|c|c|c|c|c|c|c|c|c|}
\hline MASS & VOLUME & HEIGHT & $\mathrm{A}_{\mathrm{x}}$ & $\mathrm{A}_{\mathrm{y}}$ & $\mathrm{A}_{\mathrm{z}}$ & $\mathrm{C}_{\mathrm{dx}}$ & $\mathrm{C}_{\mathrm{dy}}$ & $\mathrm{C}_{\mathrm{dz}}$ \\
\hline $200 \mathrm{~kg}$ & $0.0657 \mathrm{~m}^{3}$ & $0.203 \mathrm{~m}$ & $0.0324 \mathrm{~m}^{2}$ & $0.431 \mathrm{~m}^{2}$ & $0.431 \mathrm{~m}^{2}$ & 0.004 & 1 & 1 \\
\hline
\end{tabular}




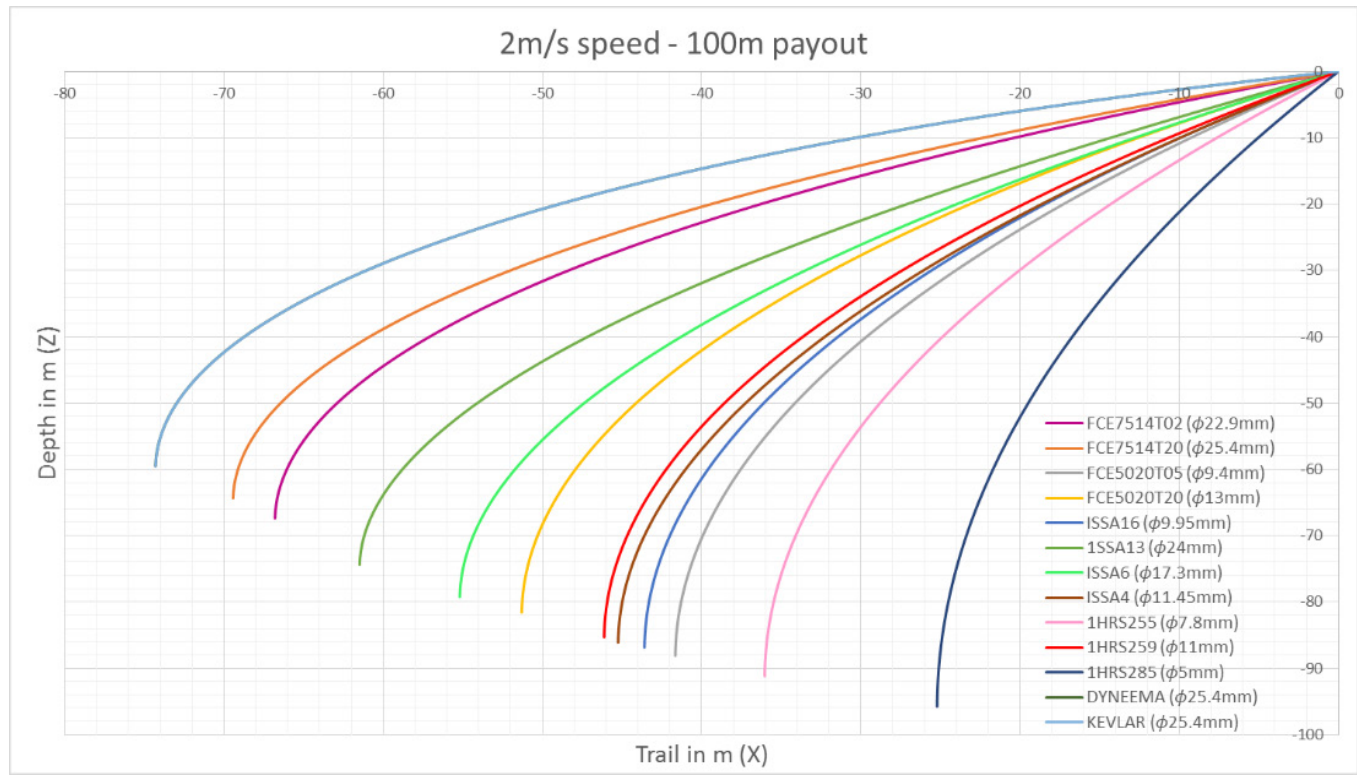

Figure 2. Cable profile of cables for a payout of $100 \mathrm{~m}$ at $2 \mathrm{~m} / \mathrm{s}$ speed.

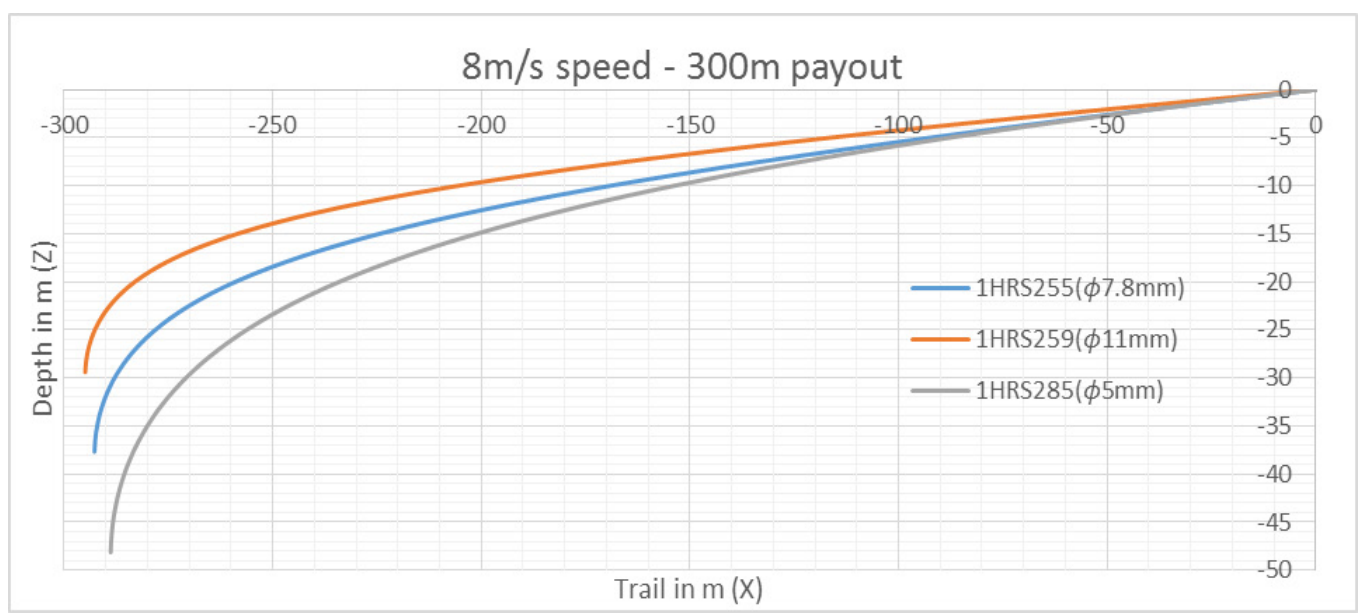

Figure 3. Cable profile of $1 \mathrm{HRS}$ series cables for a payout of $300 \mathrm{~m}$ at $8 \mathrm{~m} / \mathrm{s}$ speed $\mathrm{s}$ cables

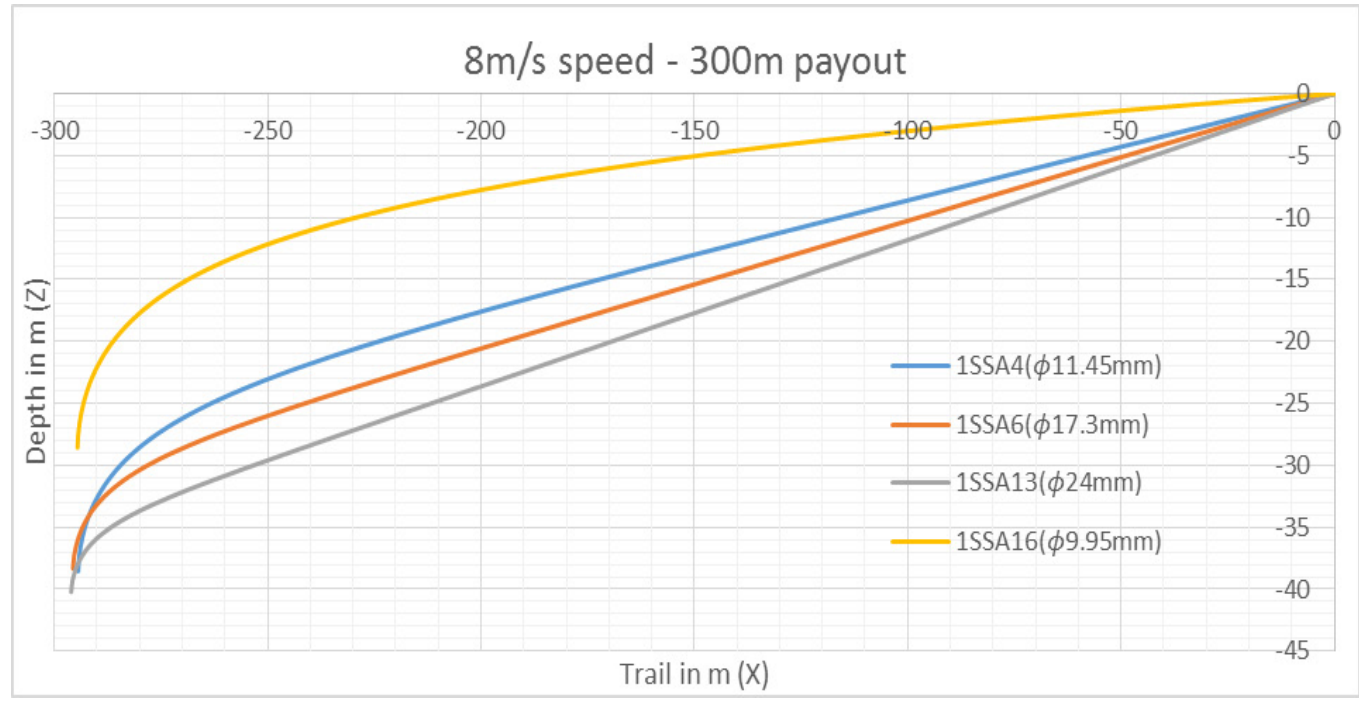

Figure 4. Cable profile of $1 \mathrm{SSA}$ serie for a payout of $300 \mathrm{~m}$ at $8 \mathrm{~m} / \mathrm{s}$ speed. 


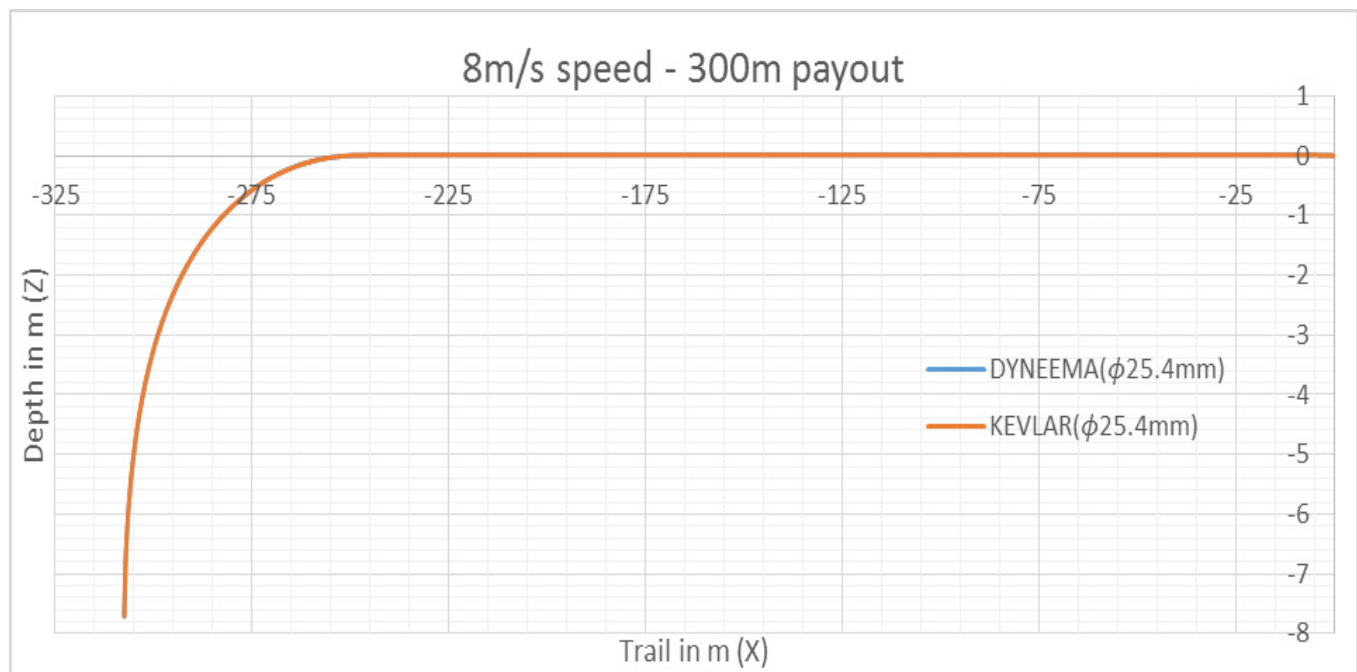

Figure 5. Cable profile of positively buoyant cables for a payout of $300 \mathrm{~m}$ at $8 \mathrm{~m} / \mathrm{s}$ speed

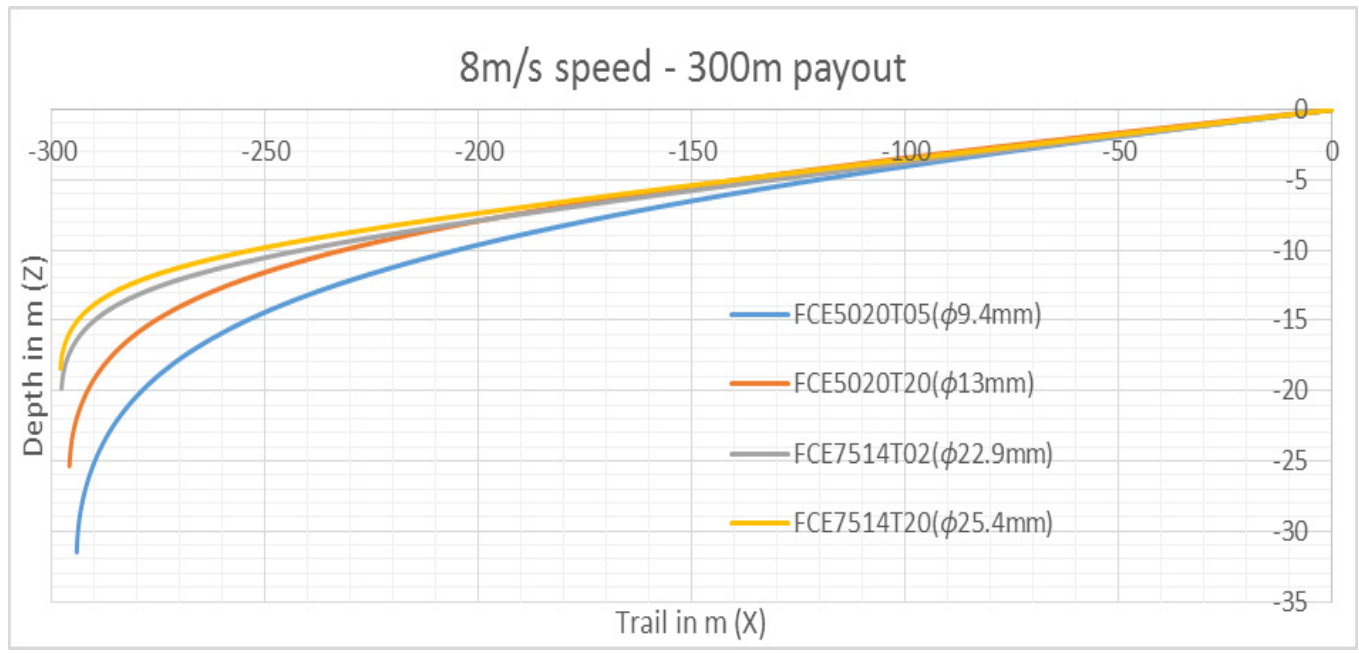

Figure 6. Cable profile of FCE series cables for a payout of $300 \mathrm{~m}$ at $8 \mathrm{~m} / \mathrm{s}$ speed.

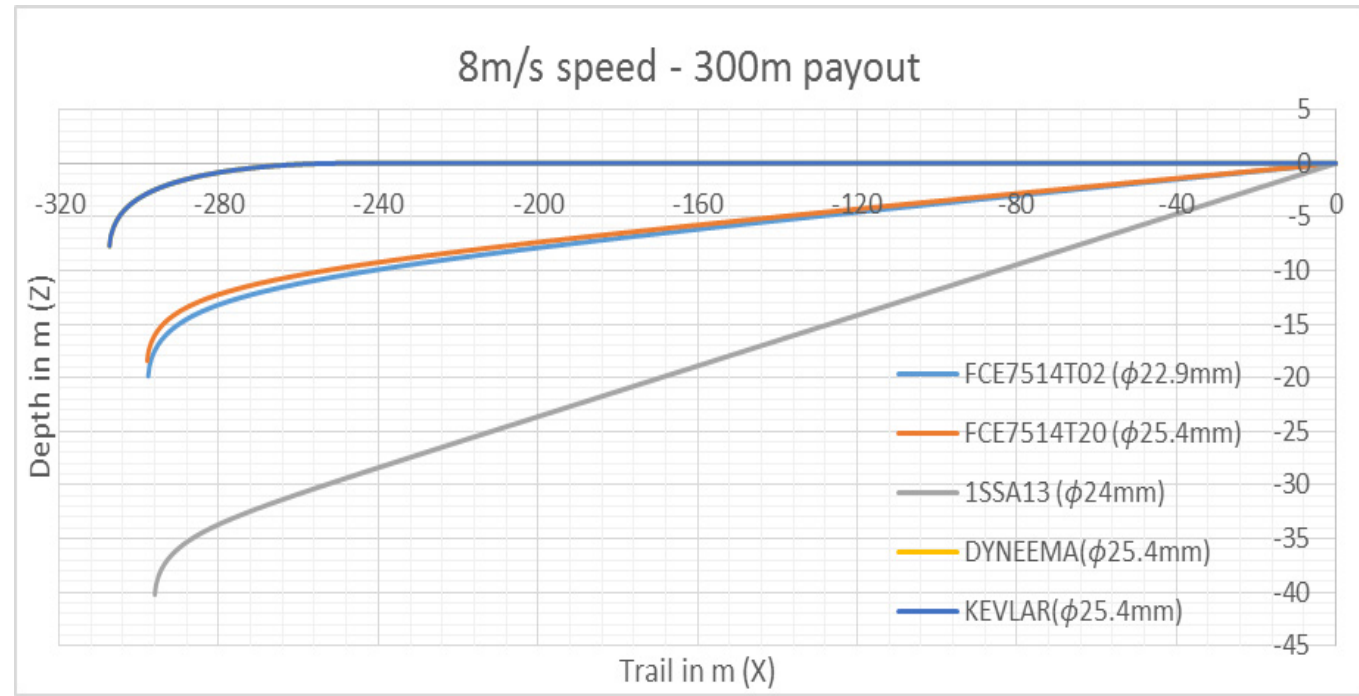

Figure 7. Cable profile of cables for a payout of $300 \mathrm{~m}$ for at $8 \mathrm{~m} / \mathrm{s}$ speed 


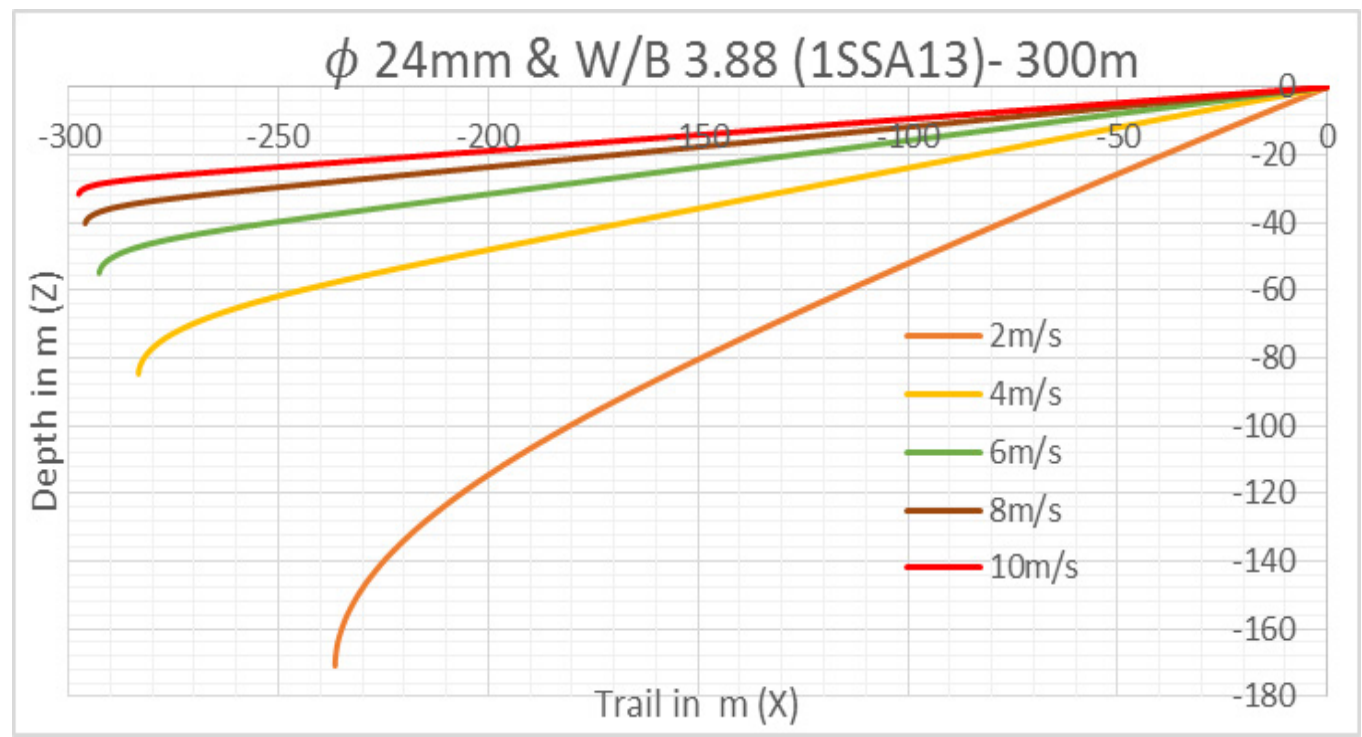

Figure 8. Cable profile of $1 \mathrm{SSA} 13$ for a payout of $300 \mathrm{~m}$ different speeds

Cable profile achieved by each cable for a given payout at different speeds are plotted, which represents the catenary profile variation of the cables.

Among the selected tow cables, light tow cable 1HRS285 ( $\phi 5 \mathrm{~mm}$ and W/B 1.39) attained the maximum depth and minimum trail for all payouts at $2 \mathrm{~m} / \mathrm{s}$ and $8 \mathrm{~m} / \mathrm{s}$ speeds. But among light tow cables of FCE series, FCE5020T05 ( $\phi 9.4 \mathrm{~mm}$ and W/B 1.36) attained the maximum depth and minimum trail for all payouts at $2 \mathrm{~m} / \mathrm{s}$ and $8 \mathrm{~m} / \mathrm{s}$ speeds. In case of light tow cables, we observed that the cables with smaller diameter and lower W/B ratio attains the maximum depth. i.e, As the diameter and W/B ratio of light weight tow cables increases, the depth attained by cable decreases and the trail attained by the cable increases, probably because smaller diameter cables experience less drag than larger ones.

But in case of heavy tow cables, cables of greater diameter attains greater depth than cables with smaller diameter for greater payouts and speed. Among those cables, heavy tow cables (1SSA) with high weight to buoyancy ratio have the maximum effective depth at different tow speeds. But, on considering the weight of those cables in air, the self-weight of cable for its whole length are sometimes greater than the load at the end node provided. The light tow cables (1HRS255 and 1HRS285) have a range of depth and trail similar to that are achieved by heavy tow cables.

Fig 2 represents the cable profile of all selected cables for a payout of $100 \mathrm{~m}$ at $2 \mathrm{~m} / \mathrm{s}$ speed. It reveals that light tow cables (IHRS285 with $\phi 5 \mathrm{~mm}$ and W/B 1.39) achieved the maximum depth and minimum trail, while the positively buoyant cables $(\phi 25.4 \mathrm{~mm}$ and W/B $0.002 \& 0.003)$ attained the minimum depth and maximum trail. Fig 3 to fig 6 represents the cable profile of each series cables for a given payout at a given speed. It reveals the influence of diameter and W/B ratio of cables in attaining the depth.
The cables that attained maximum depth and minmum depth of same series are distinguished by the properties of diameter and weight by buoyant ratio. From fig 6 , dyneema and kevlar are positively buoyant cables of similar properties and they attained same cable profiles, hence the cable profile overlaps. Fig 7 represents the cable profile of cables with similar diameter for a given payout at a specific speed. Fig 8 represents the cable profile attained by a cable for a given payout at different speeds. It gives an idea about the towspeed to attain a certain depth for a given payout

\section{Conclusions}

Analysis was performed on a series of commercially available tow cables to study the dependency of tow depth on tow speed and cable properties (diameter and weight by buoyant ratio). The payout length that has to be provided to achieve a certain depth can also be roughly estimated for those cables from the analysis results.

Buoyancy of the cable have significant role in attaining the tow depth along with the tow speed. Light weight cables of smaller diameter are capable to achieve depths similar to that of heavy tow cables under their breaking strength. In case of light weight tow cables, as the diameter and $\mathrm{W} / \mathrm{B}$ ratio of light weight tow cables increases, the depth attained by cable decreases and the trail attained by the cable increases. This is probably due to the fact that an increased diameter attracts more drag which influence the depth achieved. Among the selected cables, the light weight cable $1 \mathrm{HRS} 285 \phi 5 \mathrm{~mm}$ and W/B 1.39) attains the maximum depth under its breaking strength. Among light tow cables (FCE and 1HRS series), smaller diameter cables achieved deeper depth and minimum trail for a given payout and speed.

Positively buoyant cables stretches under loading at high 
tow speeds and are not suitable for deep towing except at slow speeds. They are suitable for surface towing under their breaking strength. The work can be further extended at different loads and for different seastate conditions.

\section{REFERENCES}

[1] Buckham, B., Nahon, M., Seto, M., Zhao, X. and Lambert, C.(2003). Dynamics and Control of a Towed Underwater Vehicle System, part I: Model development, Ocean Engineering, Vol 30, pp. 453-470.

[2] Francis, R., Sudarsan, K., Krishnankutty, P. and Ananthasubramanian, V. (2012). Design and Analysis of A Towed Submersible System, IJIRD, Vol 1, Issue. 10, pp. 300-317.

[3] Perrault, D E., Hackett, G. and Nahon, M. (1997). Simulation and Active Control of Towed Undersea Vehicles, IEEE, pp. 1277-1282.

[4] Williams, C. D., Curtis, T., Doucet, J. M., Issac, M. T. and Azarsina, F. (2006). Effects of Hull Length on the Hydrodynamic Loads on a Slender Underwater Vehicle during Manoeuvres, Proceedings of the MTS/IEEE OCEANS '06, Boston Conference.

[5] Thomas, N.,(2017), Analysis of Tow Cables, M.Tech thesis, Department of Ship Technology, Cochin University of Science and Technology.

[6] FALMAT manual, (2017).

[7] http://falmat.com/products/marine-subsea/towcables/, (accessed on April 2017).

[8] NOVACAVI Brochure (2017).

[9] www.novacavi.it/downloads/aquancable-marine-coax-towcable.pdf, (accessed on April 2017).

[10] Orcaflex manual (2017).

[11] https://www.orcina.com/SoftwareProducts/OrcaFlex/Docu mentation/Help/, (accessed on April 2017).

[12] Pelicanrope Brochure 1 (2017). http://www.pelicanrope.com/12-strand-single-braid-dynee ma.html (accessed on April, 2017).

[13] Pelicanrope Brochure 2 (2017). http://www.pelicanrope.com/12-strand-single-braid-kevlar. html (accessed on April, 2017). 